\title{
Investigation of Biocide Biodegradation in Wastewater under Laboratory Set-Up in Anaerobic, Aerobic and Aerobic with Substrate Conditions
}

Rupa Chand", Tiberiu Tulucan and Mariana Aburlacitei

Department of Civil Engineering, Aalborg University, Denmark

\begin{abstract}
In this study the biodegradation of five biocides such as Isoproturon (IP), Octyl-isothiazolinone (OIT), Terbutryn (TB), Cybutryne, Irgarol (IRG) and Tebuconazole (TBU) in raw wastewater have been investigated. The laboratory experiment was performed under three conditions as aerobic, anaerobic and aerobic with substrate (molasses). The biocides concentration was detected using High Pressure Liquid Chromatography coupled with Mass Spectrometer (HPLC-MS). This was conducted to quantify the biodegradation of biocides in wastewater. Under these three conditions investigated Isoproturon (IP) had no clear degradation. Octyl-isothiazolinone (OIT) is significantly biodegraded in all three conditions. Terbutryn (TB), Cybutryne, Irgarol (IRG) and Tebuconazole (TBU), investigated are slowly biodegradable. From the experiment, it is observed that aerobic with substrate condition is most suitable for biodegradation of the selected biocides.
\end{abstract}

Keywords: Biocide; Biodegradation; Raw wastewater; Anaerobic; Aerobic; Substrate

\section{Introduction}

We have right to enjoy healthy life, food without contamination from the poisons, clean domestic kitchens, bathrooms, toilets and pathogen free hospitals, restaurants, hotels, farms, shops, supermarkets and all surrounding around us. Worldwide biocides are being used for getting rid from different daily life problems including bacterial, fungal, allergic, fouling and other microbial activities. The continuous use of biocidal products increasing with number of applications [1] and hundreds of products are used in low concentration in fabrics and cleans claiming for help in controlling infection. Biocides use in buildings as in-can preservative, façade coatings [2], preservative for leather or rubber and industrial working fluids [3]. In time perspective, the chemical biocides have been used for centuries, initially for food and water preservation $[1,4-6]$. It can be said that the biocides are useful for protecting the public health and environment from disease causing agents. Consequently, the biocidal products have various environmental impacts and create threats to the public health in several ways. Regarding the specificity, toxicity and composition biocides pose a real danger for the existence and health of human and animals [7].

More truthful facts about biocides are related with bacterial resistance to low concentration. In most cases low to intermediate resistance have been observed but sometime high concentration resistance has been found [8,9]. The biocidal activity depends upon number of factors including the concentration, contact time, organic load, formulation, temperature, $\mathrm{pH}$, presence of biofilm, type of micro-organisms and number of micro-organisms [1]. In many cases the resistance or adaptation of the micro-organisms is because of the changing environment [10].

Water is dominant agent that carries the biocides used in agriculture, private households and discharge to the recipients or to waste water treatment plants. griculture has been supposed to be the major source of biocide pollution throughout the years [11]. It could be seen that municipal wastewater is one of the main exposure route that brings the biocidal products into the environment [12] because it has limited ability of removal of biocides from the wastewater. Similarly, the chemicals from the agricultural sites and polluted soils reach to the wastewater during the wet season or sometime could directly discharges to the recipient during peak wet season. After being used for several purposes, the biocides are discharged into sewerage systems and reach to wastewater treatment plant [13-16] where with conventional treatment processes they cannot be removed completely, thus finally they reach to the recipient area [15-18] such as rivers and streams. At present, biocides pollutants from the building and construction materials getting increased [11-19] and hence these sources are also gaining attention for pollution in watercourses for such organic pollutants [11].

The selected biocides Isoproturon (IP), Octyl-isothiazolinone (OIT), Terbutryn (TB), Cybutryne, Irgarol (IRG) and Tebuconazole (TBU) are used in paints, household cleaning products, personal care products, coatings, textiles, paper coating materials, leather, laundry, renders, wood preserver and agricultural areas. These all biocide could reach to waste water plants through sewer system. The waste water plants become the conveyor to the recipient such as rivers, lakes, estuaries and oceans. So it is necessary to collect the contaminated water and proceed for the treatment which can be accomplished by physical, chemical and biological processes [20]. Scientists and the researcher need to focus on efficient reduction in the treatment system in order to decrease the harmful impact on environment particularly to the aqueous environment.

In present study the major objective is to evaluate degradation by micro-organisms (biodegradation) of biocides in wastewater. More specific aim of the project is to quantify the degradation of biocides in different conditional set ups in laboratory and also to find suitable condition for degradation in wastewater. For this purpose, batch experiment was set up in laboratory with three conditions; as anaerobic, aerobic with substrate (molasses) and aerobic without substrate.

\section{Kinetics of biodegradation}

In this report, the kinetics for biodegradation is described by;

*Corresponding author: Rupa Chand, Department of Civil Engineering Aalborg University, 9100 Aalborg, Denmark, Tel: +45 994099 40; E-mail: chandrupa.env@hotmail.com

Received December 11, 2017; Accepted January 23, 2018; Published January 27,2018

Citation: Chand R, Tulucan T, Aburlacitei M (2018) Investigation of Biocide Biodegradation in Wastewater under Laboratory Set-Up in Anaerobic, Aerobic and Aerobic with Substrate Conditions. J Civil Environ Eng 8: 295. doi: 10.4172/2165784X.1000295

Copyright: () 2018 Chand $R$, et al. This is an open-access article distributed under the terms of the Creative Commons Attribution License, which permits unrestricted use, distribution, and reproduction in any medium, provided the original author and source are credited. 
$\mathrm{r}=\mathrm{k} \mathrm{C} \mathrm{C}^{\mathrm{n}}$

Where, $r=$ Reaction rate $\left(M / L^{3} / T\right)$

$\mathrm{k}=$ Reaction constant $(1 / \mathrm{T})$

$\mathrm{C}=$ Reagent concentration $\left(\mathrm{M} / \mathrm{L}^{3}\right)$

$\mathrm{n}=$ Reaction order (zero to second order)

The quantified decreasing of the biocide concentration is considered the first order degradation. Basically, it is based on the assumption that the reaction rate is directly proportional to biocide concentration and also various reactions in sewage treatment follows first order kinetics [21]. Taking logarithm on both sides gives;

$\log r=\log k+n \log C$

The rate of the change of concentration $(\mathrm{dC} / \mathrm{dt})$ of the pollutant is proportional to the pollutant concentration at given time. The associated reaction can be mentioned as;

$(\mathrm{dC} / \mathrm{dt})=-\mathrm{k} . \mathrm{C}$

Integrating the equation 1.3 with $\mathrm{C}=\mathrm{C}_{\mathrm{o}}$ at $\mathrm{t}=0$, it gives;

In $\mathrm{C}=\mathrm{In} \mathrm{C}_{0}-\mathrm{k} \cdot \mathrm{t}$

$\mathrm{k}=\left(\mathrm{In} \mathrm{C}_{0}-\right.$ In $\left.\mathrm{C}\right) / \mathrm{t}$

And further it gives;

$\mathrm{C}=\mathrm{C}_{0} \cdot \mathrm{e}^{-\mathrm{kt}}$

\section{Materials and Methods}

\section{Sampling}

The raw waste water samples were taken from the Aalborg West Wastewater Treatment Plant (AWWTP). The sampling was performed after some days of raining, due to that it has been more diluted than usually. This was taken after the removal of grease compounds and mechanical processes. After the sample was collected, it has been stored in the fridge for 7 days before the experiment begun. The laboratory experiment lasted for 14 days.

\section{Analytical procedure}

Here, $500 \mathrm{ml}$ of wastewater sample was spiked with $1.25 \mathrm{mg}$, with a concentration of $0.25 \mathrm{ml} / \mathrm{l}$, stock solution of biocide Isoproturon (IP), Octyl-isothiazolinone (OIT), Terbutryn (TB), Cybutryne, Irgarol (IRG) and Tebuconazole (TBU). To simulate the conditions from a wastewater facility, the experiment consists in 6 samples: 2 samples that simulate anaerobic conditions that at the beginning of the experiment were flushed with $\mathrm{N}_{2}$ to remove the oxygen; 2 samples simulate aerobic condition; 2 samples simulate aerobic conditions in which molasses was added as substrate. The experiment was conducted for 14 days to see computable reduction in the biocide concentration. The samples extracted were taken after 1 hour of the addition of biocides, after 24 hours, after 7 days and 14 days. For aerobic samples it has been necessarily to be flushed with compressed air (CA), daily, approximately at the same hour. In all that time the samples were placed on a shaking table with $120 \mathrm{rpm}$.

The method chosen for analyzing the samples is HPLC-MS (High Performance Liquid Chromatography with Mass Spectrometry) using electrospray ionization in positive mode $(\operatorname{ESI}(+))$ on an Ultimate 3000 HPLC-system coupled to an MSQ Plus single quadrupole Mass Spectrometer (Thermo Scientific). The separation is performed at $30^{\circ} \mathrm{C}$ using Synergy polar-RP column $(\mathrm{L}=150 \mathrm{~mm}, \mathrm{ID}=2 \mathrm{~mm}$, particles $=4$ $\mu \mathrm{m}$, Phenomenex, Torrance, CA, USA). A multi-step gradient of water with $0.1 \%$ formic acid (A) and acetonitrile with $0.1 \%$ formic acid (B) is used: $0-1 \min 30 \%$ B, $1-10 \min 30-90 \%$ B, 10-14 min 90\% B, 14-19 min, $30 \% \mathrm{~B}$. Before the samples were analyzed it had been added 2 internal standards TB-D5 and IRG-D9.

\section{Results and Discussion}

\section{Biodegradation in chosen conditions}

Selected biocides were spiked with the same starting concentration of $0.25 \mathrm{mg} / \mathrm{l}$. They were present in all three conditions performed but with slightly different concentrations between them after one hour of the experimental set up. All the samples have a duplicate and named as 'A' and 'B'. The results from the experiment are presented in Table 1.

The graphical representation for Isoproturon (IP) presented in following Figure 1, is the concentrations during all three conditions. It can be seen that the concentration for this biocide are slowly increasing in the graphic, but when the starting concentration $(0.25 \mathrm{mg} / \mathrm{l})$ is compared with the last analysis performed there is a minor decreasing. Although, when the final values compared with the one hour recovery amount, the concentration for IP is slightly increased. For the anaerobic condition the final concentrations are $0.2317 \mathrm{mg} / \mathrm{l}$ for ' $\mathrm{A}$ ' sample and $0.2198 \mathrm{mg} / \mathrm{l}$ for 'B' sample. In the aerobic case condition, the final concentration for sample ' $\mathrm{A}$ ' is $0.2387 \mathrm{mg} / \mathrm{l}$ and for sample ' $\mathrm{B}$ ' is 0.241 $\mathrm{mg} / \mathrm{l}$; for aerobic plus substrate the values are $0.2339 \mathrm{mg} / \mathrm{l}$ for sample ' $\mathrm{A}$ ' and $0.2297 \mathrm{mg} / \mathrm{l}$ for sample 'B'.

From the graphic illustration for Octyl-isothiazolinone (OIT), all three conditions show that during the experiment this compound is degraded before 7 days. After this time period this compound had none detectable values. The final concentration for the analysis has been taken for the 24 hours. For anaerobic condition, the final concentrations are $0.0593 \mathrm{mg} / \mathrm{l}$ for sample 'A' and $0.0373 \mathrm{mg} / \mathrm{l}$ for sample 'B'. For aerobic, the final concentrations are $0.0371 \mathrm{mg} / \mathrm{l}$ for sample 'A' and $0.0285 \mathrm{mg} / \mathrm{l}$ for sample 'B'. For aerobic plus substrate the values are $0.0049 \mathrm{mg} / \mathrm{l}$ for sample 'A' and $0.0038 \mathrm{mg} / \mathrm{l}$ for sample 'B'.

Other three biocides, Terbutryn (TB), Cybutryne, Irgarol (IRG) and Tebuconazole (TBU), in all three conditions are slowly degradable. For Terbutryn (TB), in anaerobic condition the concentration after 14 days are $0.147 \mathrm{mg} / \mathrm{l}$ for sample 'A' and $0.1206 \mathrm{mg} / \mathrm{l}$ for sample 'B', for aerobic condition are $0.1485 \mathrm{mg} / \mathrm{l}$ for sample 'A' and $0.1298 \mathrm{mg} / \mathrm{l}$ for sample 'B'. In the last case, aerobic plus substrate, the values are $0.13 \mathrm{mg} / \mathrm{l}$ for sample 'A' and $0.1275 \mathrm{mg} / \mathrm{l}$ for sample 'B'. For Cybutryne, Irgarol (IRG), the final concentrations values are, in anaerobic case, $0.1267 \mathrm{mg} / \mathrm{l}$ for sample 'A' and $0.0939 \mathrm{mg} / \mathrm{l}$ for sample 'B'. In aerobic case, $0.1136 \mathrm{mg} / \mathrm{l}$ for sample 'A' and $0.0968 \mathrm{mg} / \mathrm{l}$ for sample 'B'. In aerobic plus substrate condition, the values are $0.1027 \mathrm{mg} / \mathrm{L}$ for sample 'A' and $0.1048 \mathrm{mg} / \mathrm{l}$ for sample 'B'. For Tebuconazole (TBU), the values in the anaerobic condition are $0.1267 \mathrm{mg} / \mathrm{l}$ for sample 'A' and $0.0939 \mathrm{mg} / \mathrm{l}$ for sample 'B'. For aerobic condition the final concentration for sample ' $A$ ' and ' $B$ ' are $0.1136 \mathrm{mg} / \mathrm{l}$ and $0.0968 \mathrm{mg} / \mathrm{l}$ respectively. In aerobic plus substrate condition, the values are $0.1027 \mathrm{mg} / \mathrm{l}$ for sample 'A' and $0.1048 \mathrm{mg} / \mathrm{l}$ for

\begin{tabular}{|c|c|c|c|c|c|}
\hline Conditions & IP & OIT & TB & IRG & TBU \\
\hline Anaerobic A & 0.2377 & 0.1783 & 0.1935 & 0.1973 & 0.1794 \\
\hline Anaerobic B & 0.2073 & 0.1605 & 0.1769 & 0.1811 & 0.1667 \\
\hline Aerobic A & 0.2407 & 0.1685 & 0.1925 & 0.1979 & 0.1786 \\
\hline Aerobic B & 0.2166 & 0.1643 & 0.1845 & 0.1935 & 0.1742 \\
\hline Aerobic + Substrate A & 0.2372 & 0.1548 & 0.1862 & 0.1917 & 0.1724 \\
\hline Aerobic + Substrate B & 0.2252 & 0.1509 & 0.1882 & 0.1969 & 0.1768 \\
\hline
\end{tabular}

Table 1: Initial concentrations of selected biocides in $(\mathrm{mg} / \mathrm{l})$. 
Citation: Chand R, Tulucan T, Aburlacitei M (2018) Investigation of Biocide Biodegradation in Wastewater under Laboratory Set-Up in Anaerobic, Aerobic and Aerobic with Substrate Conditions. J Civil Environ Eng 8: 295. doi: 10.4172/2165-784X.1000295

Page 3 of 9

sample 'B'. All three biocides have approximately the same tendency and close concentrations values.

Averaged concentration of these biocides throughout the experimental period has been shown in Figure 1.

As graphics shown in Figure 1, there is sudden degradation of OIT in all three conditions in 24 hours of experimental set up. It gives about $28.5 \%, 19.7 \%$ and $2.8 \%$ degradation at respective anaerobic, aerobic and aerobic with substrate condition in comparison to 1 hour of recovery period. Likewise, for the same biocide component during whole experiment period of 336 hours, there is no detectable amount found. Furthermore, in 24 hours TB shows slow degradation of $99.1 \%, 98.7 \%$ \& $80.07 \%$ and at 336 hours it reaches to $72.23 \%, 73.81 \%$ and $68.78 \%$ for anaerobic, aerobic and aerobic with substrate conditions respectively. Again, in 24 hours of experimental time there is no decreasing of IRG in anaerobic and aerobic conditions, but it reaches $82.08 \%$ for aerobic with substrate condition. At 336 hours of total experimental time it reaches to $68.85 \%, 71.08 \%$ and $66.53 \%$ with these three conditions. TBU is also slowly decreased at 24 hours and found $98.22 \%$ for anaerobic and $82.32 \%$ for aerobic with substrate condition but found slightly higher in comparison to first hour in aerobic condition. At last hour of experiment it found $63.72 \%, 59.61 \%$ and $59.42 \%$ with respective anaerobic, aerobic and aerobic with substrate conditions.

\section{Biodegradation constant $(k)$ values}

The calculated first order degradation constant values in laboratory for all selected biocides have been summarized in Table 2. Comparing all three conditions it is clearly noticed that biodegradation is large enough in aerobic with substrate condition. The substrate addition to the medium brings measurable changes in the metabolism of the bacteria [22]. The added substrate, molasses is a source of carbon for the involved bacteria in the degradation process. The presence of substrate allows the bacteria to grow which break down or partially convert to
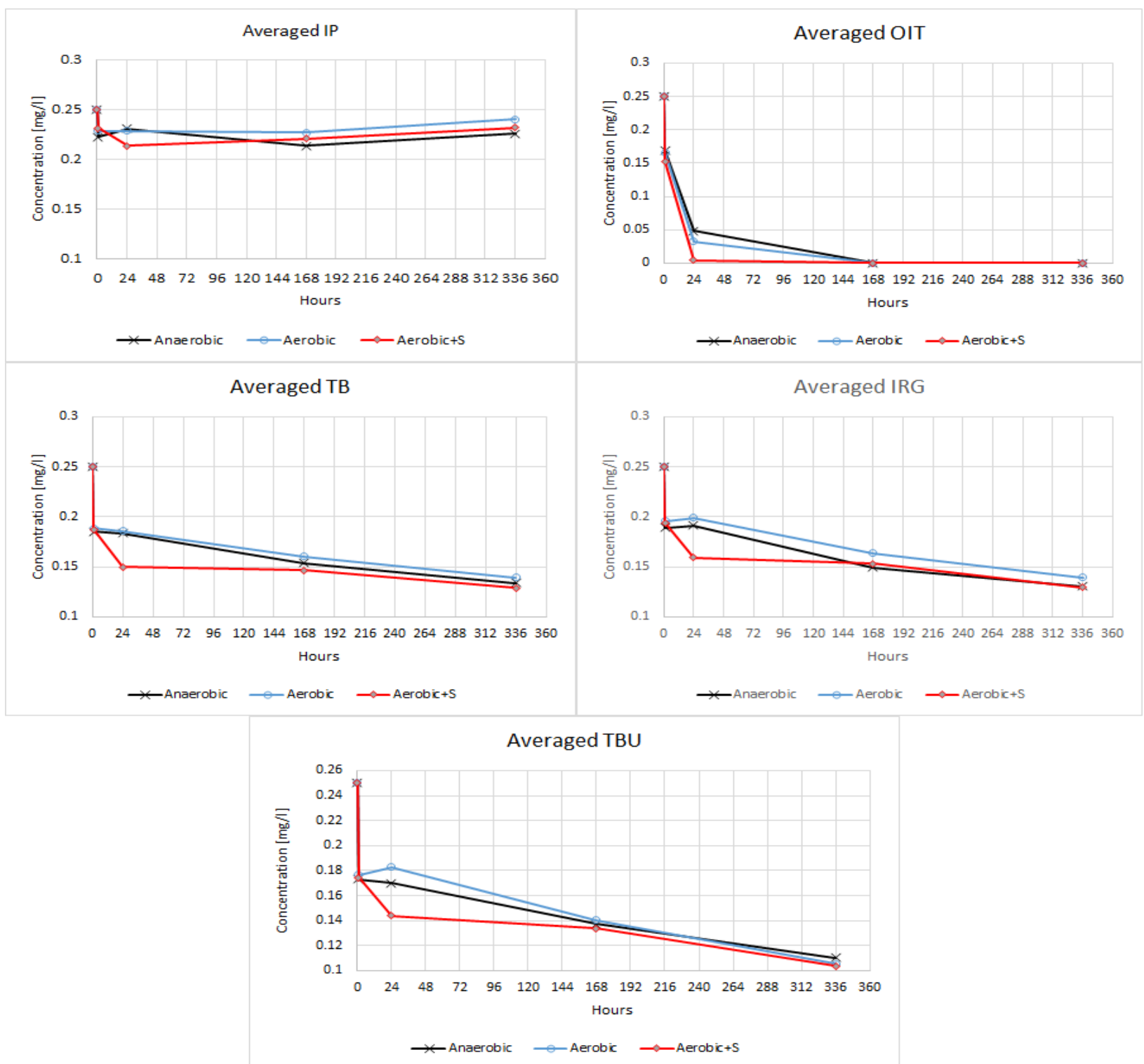

Figure 1: Average concentration of the selected biocides throughout the experiment. 
Citation: Chand R, Tulucan T, Aburlacitei M (2018) Investigation of Biocide Biodegradation in Wastewater under Laboratory Set-Up in Anaerobic, Aerobic and Aerobic with Substrate Conditions. J Civil Environ Eng 8: 295. doi: 10.4172/2165-784X.1000295

Page 4 of 9

\begin{tabular}{|c|c|c|c|c|c|}
\hline \multirow{2}{*}{ Conditions } & \multicolumn{5}{|c|}{ Biocides } \\
\cline { 2 - 6 } & IP $^{\star}$ & OIT & TB & IRG & TBU \\
\hline Anaerobic & -0.000043 & 0.054551 & 0.000971 & 0.001114 & 0.001345 \\
\hline Aerobic & -0.000143 & 0.070601 & 0.000906 & 0.001019 & 0.001544 \\
\hline Aerobic + Substrate & -0.000008 & 0.155254 & 0.001117 & 0.001216 & 0.001554 \\
\hline
\end{tabular}

*Negative biodegradation constant may be error factors in experimental procedure or instrumental detection error.

Table 2: Measured biodegradation rate $(\mathrm{k})$ constant (in $\left.\mathrm{h}^{-1}\right)$.

the trace pollutant [23]. With increase in bacterial population the degradation rate get increased.

In general, biological degradation (biodegradation) is usual practice in wastewater treatment plants both in activated sludge treatment and biological filtration [24]. But the long half-lives for biodegradation has limted its effect on biocide degradation. Co-metabolism activities of the micro-organisms are responsible for degradation of the organic substance and the degradation can occur in anoxic, anaerobic and aerobic condition. As mentioned earlier, most of the organic pollutants follow the first order degradation. From batch experiment it can be easily noticed that Isoproturon (IP) has no degradation. Instead it is increasing in concentration. It may be due to some error factors during the experimental set up or in detecting into chromatography. Also it has been found that Isoproturon (IP) has very low degradability due to its low solubility in water which limits it bioavailability [25] and also nitrogen-containing organic compounds may not be easily biodegraded in the system [26,27]. In both, aerobic and anaerobic condition the biodegradation of Isoproturon is not detected throughout the experiment [20].

Broad spectrum used, Octyl-isothiazolinone (OIT) is non-persistent and readily biodegradable [28] antifungal products. The higher degradation rate of OIT is also related with the water solubility (309 $\mathrm{mg} / \mathrm{L}$ ) which enhance the bioavailability of the product [25]. Detected biodegradation rate constant for OIT ranges in between $0.05455 \mathrm{~h}^{-1}$ to $0.15525 \mathrm{~h}^{-1}$ in anaerobic to aerobic with substrate conditions.

Other compounds including Terbutryn (TB), Cybutryne, Irgarol (IRG) and Tebuconazole (TBU) have similar trend of degradation. Terbutryn (TB) is mainly used in construction material and is susceptible for microbial degradation [29] and through rain water contact reach to surface waters which create adverse effect on aquatic organisms. From experiment, the obtained value for degradation constant ranges between $0.000906 \mathrm{~h}^{-1}$ to $0.001117 \mathrm{~h}^{-1}$ in aerobic and aerobic with substrate condition.

Cybutryne, Irgarol (IRG) is reported stable under natural condition [30]. Its degradation in water column and also in sediment is slow [31]. The obtained degradation constant value varies in between $0.001019 \mathrm{~h}^{-1}$ to $0.001216 \mathrm{~h}^{-1}$ in aerobic and aerobic with substrate conditions. This compound is reported as hydrolytically stable in water with $\mathrm{pH}$ 5-9 and degraded $17 \%$ and $1 \%$ in 28 days at the concentration of $10 \mathrm{mg} / \mathrm{l}$ and 20 $\mathrm{mg} / \mathrm{l}$ respectively [32].

The biodegradation rate constant of Tebuconazole (TBU) is found in between $0.001345 \mathrm{~h}^{-1}$ to $0.001554 \mathrm{~h}^{-1}$ in anaerobic and aerobic with substrate condition respectively. TBU is persistent fungicide [33] and widely used to control soil-borne and foliar diseases in the crops. The azole fungicides were observed slow degradation in water [34] and have long persistent effect on aqueous environment.

The Board for the Authorization of Plant Protection Products and Biocides, based on biodegradation screening tests, has classified biocides depending on the rate of biodegradation constant ' $\mathrm{k}$ ' [35].

\begin{tabular}{|c|c|c|}
\hline Test results/biodegradability & Minimum constant k & Half-life \\
\hline Readily biodegradable & $0.047 \mathrm{~d}^{-1}\left(1.128 \mathrm{~h}^{-1}\right)$ & $15 \mathrm{~d}(360 \mathrm{~h})$ \\
\hline $\begin{array}{c}\text { Readily biodegradable (but failing 10- } \\
\left.\text { days window }{ }^{\star}\right)\end{array}$ & $0.014 \mathrm{~d}^{-1}\left(0.336 \mathrm{~h}^{-1}\right)$ & $50 \mathrm{~d}(1200 \mathrm{~h})$ \\
\hline Inherently biodegradable & $0.0047 \mathrm{~d}^{-1}\left(0.1128 \mathrm{~h}^{-1}\right)$ & $150 \mathrm{~d}(3600 \mathrm{~h})$ \\
\hline Not biodegradable & $0 \mathrm{~d}^{-1}\left(0 \mathrm{~h}^{-1}\right)$ & $\infty$ \\
\hline
\end{tabular}

Table 3: Biodegradability based on reaction constant (Source: Board for the Authorization of plant protection products and biocides, Kortekaas, 2010).

\begin{tabular}{|c|c|c|}
\hline Test results/biodegradability & Biocide type & Remarks \\
\hline Readily biodegradable & - & - \\
\hline $\begin{array}{c}\text { Readily biodegradable (but failing 10-days } \\
\text { window }{ }^{\star} \text { ) }\end{array}$ & OIT* $^{*}$ & $\begin{array}{c}\text { Aerobic + } \\
\text { Substrate }\end{array}$ \\
\hline Inherently biodegradable & OIT, TB, IRG, TBU & - \\
\hline Not biodegradable & IP & - \\
\hline
\end{tabular}

Negative biodegradation constant for Isoproturon (IP) has been not included in classification.

$\mathrm{RD}=$ Readily Biodegradable $\left(0.336<\mathrm{k} \leq 1.128 \mathrm{~h}^{-1}\right)$; $\mathrm{RD}^{\#}=$ Readily Biodegradable but Failing 10 - Days Window $\left(0.1128 \mathrm{~h}^{-1}<\mathrm{k} \leq 0.336 \mathrm{~h}^{-1}\right)$; ID=Inherently Biodegradable $\left(0 \mathrm{~h}^{-1}<\mathrm{k} \leq 0.1128 \mathrm{~h}^{-1}\right) \mathrm{ND}=$ Not Biodegradable $\left(\mathrm{k}=0 \mathrm{~h}^{-1}\right)$.

Table 4: Biodegradability type of selected biocides.

Using the values presented in Table 3 investigated biocides are classified in Table 4.

From this classification we found all biocides are inherently biodegradable in all three conditions. The only exception is Octylisothiazolinone (OIT), which in aerobic with substrate condition, is found to be readily biodegradable.

\section{Modeled concentration and Half-life for biodegradation of selected biocides}

Octyl-isothiazolinone (OIT) has a significant biodegradation. The HPLC-MS cannot detect the biocide after 7 days ( 168 hours). However, analytical model provides values for lower concentration for this compound (Figure 2). The other three biocides, including Terbutryn (TB), Cybutryne, Irgarol (IRG) and Tebuconazole (TBU) have slower rate of biodegradation. Calculated value for biodegradation rate constant from experiment is used in the model by using the equation $\mathrm{C}=\mathrm{C}_{0}$. $\mathrm{e}^{\mathrm{kt}}$ where $\mathrm{C}$ is concentration at time $t$ and $\mathrm{C}_{0}$ is initial concentration (in this case concentration after one hour of experimental set up).

Half-life for biodegradation of half concentration of the selected biocides are shown in Table 5. It is clear that the biodegradation is the common source of uncertainty. Though half - life for each condition for each selected biocide is complex but all have lower half-life in aerobic with substrate condition. It is again endorsed with larger number of microbial population with addition of substrate.

From the present laboratory experiment, the selected biocides degraded half of its amount from lesser than a week for OIT in aerobic with substrate condition to more than a month TB in aerobic. For almost all of these biocides aerobic with substrate condition has shorter half-life period. For OIT and TBU, aerobic condition has shorter halflife time than anaerobic but is opposed for TB and IRG having longer half-life with aerobic condition.

Isoproturon (IP) compound is mainly used to preserve facades and building materials [2]. It can be better degraded with hydrolysis and photodegradation in a slower rate process [24]. The half-life is more than a month [36]. But at present study we found the negative degradation constant values.

The Isothiazolinones groups are widely used biocides in cooling 
Citation: Chand R, Tulucan T, Aburlacitei M (2018) Investigation of Biocide Biodegradation in Wastewater under Laboratory Set-Up in Anaerobic, Aerobic and Aerobic with Substrate Conditions. J Civil Environ Eng 8: 295. doi: 10.4172/2165-784X.1000295

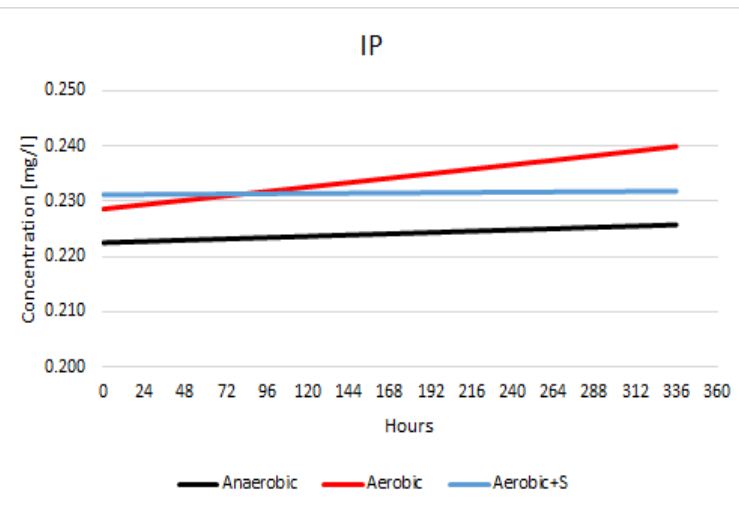

TB
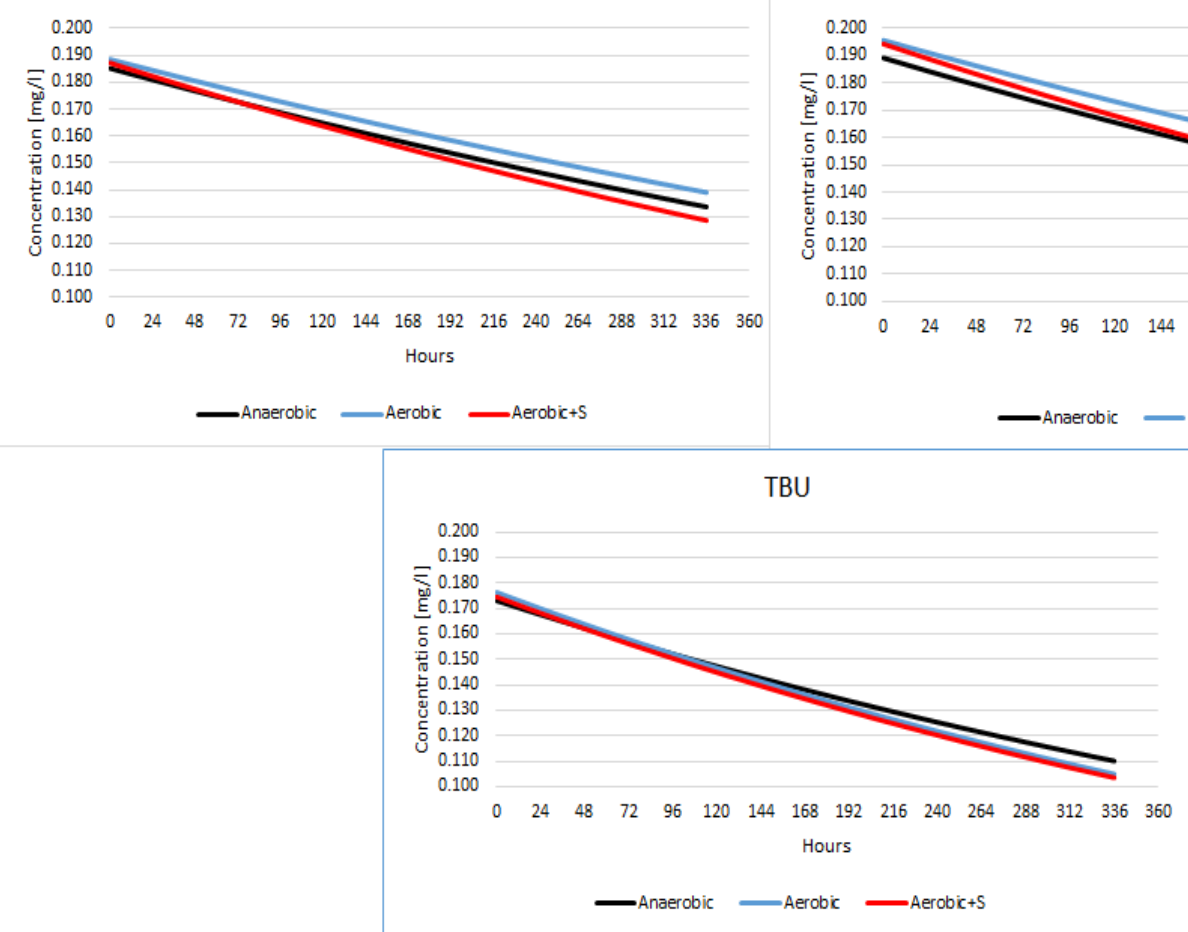

Figure 2: Modeled biocide biodegradation curve by using calculated $k\left(h^{-1}\right) ; S=$ substrate
OIT

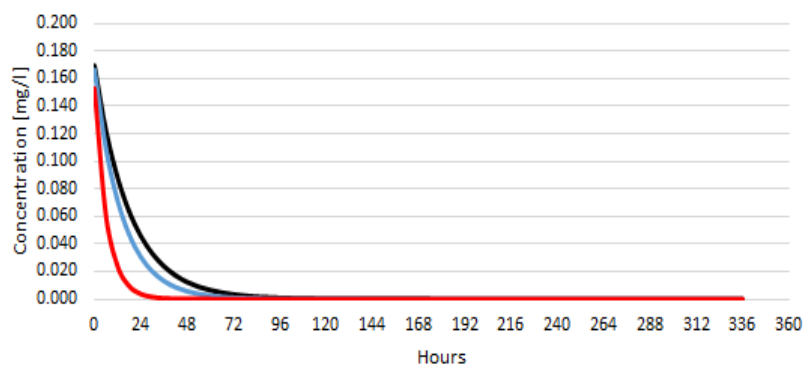

-Anaerobic -Aerobic Aerobic $+S$

IRG

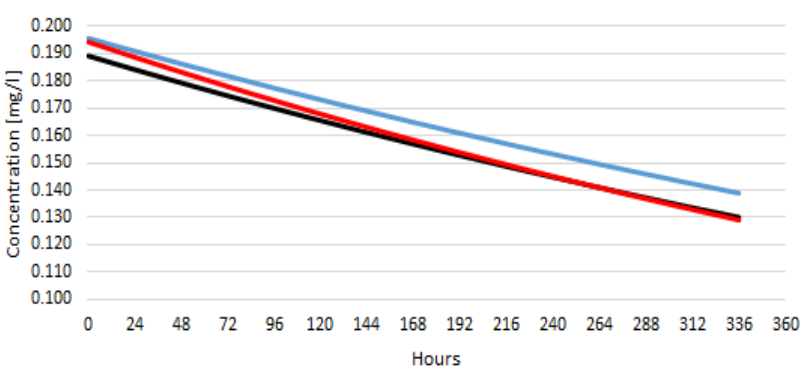

Hours

Aerobic -Aerobic $+S$

\begin{tabular}{|c|c|c|c|c|}
\hline \multicolumn{7}{|c|}{ Half-Life in hours (days) } \\
\hline Conditions & OIT & TB & IRG & TBU \\
\hline Anaerobic & 13 & $714(29$ days $)$ & $624(26$ days $)$ & 516 (22 days) \\
\hline Aerobic & 10 & $768(32$ days $)$ & $684(29$ days $)$ & 450 (19 days) \\
\hline Aerobic + Substrate & 5 & $618(26$ days $)$ & $570(24$ days $)$ & 444 (19 days $)$ \\
\hline
\end{tabular}

Table 5: Half-life of selected biocides from the modeling using first order biodegradation constant from laboratory experiment.

\begin{tabular}{|c|c|c|c|}
\hline \multirow{2}{*}{ Biocides } & \multicolumn{3}{|c|}{ Adjusted biodegradation constant $\left(\mathbf{k}_{\text {adj }} \mathbf{~} \mathbf{( h}^{-1}\right)$} \\
\cline { 2 - 4 } & Anaerobic & Aerobic & Aerobic + Substrate \\
\hline IP & 0.000009 & -0.000107 & 0.000061 \\
\hline OIT & 0.052279 & 0.067659 & 0.148789 \\
\hline TB & 0.001001 & 0.000917 & 0.001265 \\
\hline IRG & 0.001179 & 0.001015 & 0.001323 \\
\hline TBU & 0.001348 & 0.001461 & 0.001618 \\
\hline
\end{tabular}

Table 6: Adjusted biodegradation constant values $\left(\mathrm{k}_{\mathrm{adj}}\right)$ from modeled and experimental computation. water, pulp and paper water treatment, in cosmetic products, shampoos and paints [37]. These group compounds are readily degradable having the half-lives between 1 and 17 hours [38]. The half-life for OIT is found between 5 to 13 hours for aerobic with substrate and anaerobic conditions respectively. The half-life in water found 30 days [39]. Terbutryn (TB) used as weed controller [40], is not toxic to soil but toxic to aquatic animals and have tendency to bio-concentrate. The half-life in water is in between 180-240 days [41]. But in wastewater the biodegradation half-life has been found 618 to 768 hours in aerobic with substrate and aerobic conditions respectively. Cybutryne, Irgarol 1051 (IRG) using as antifouling agents and also to prevent algal growth and is persistent in water. The aquatic half-life is 100 days (2400 hours) [42]. The biodegradation of this compound is hard which however will be easily photodegraded. In this experiment we found the halflife in between 570 to 684 hours. The half-life for biodegradation of TBU compound in soil has found 49 days (1176 hours) with first order degradation [33] in laboratory test. It is quiet faster degraded in wastewater; half-life time is ranged in between 444 to 516 hours. 
Citation: Chand R, Tulucan T, Aburlacitei M (2018) Investigation of Biocide Biodegradation in Wastewater under Laboratory Set-Up in Anaerobic, Aerobic and Aerobic with Substrate Conditions. J Civil Environ Eng 8: 295. doi: 10.4172/2165-784X.1000295

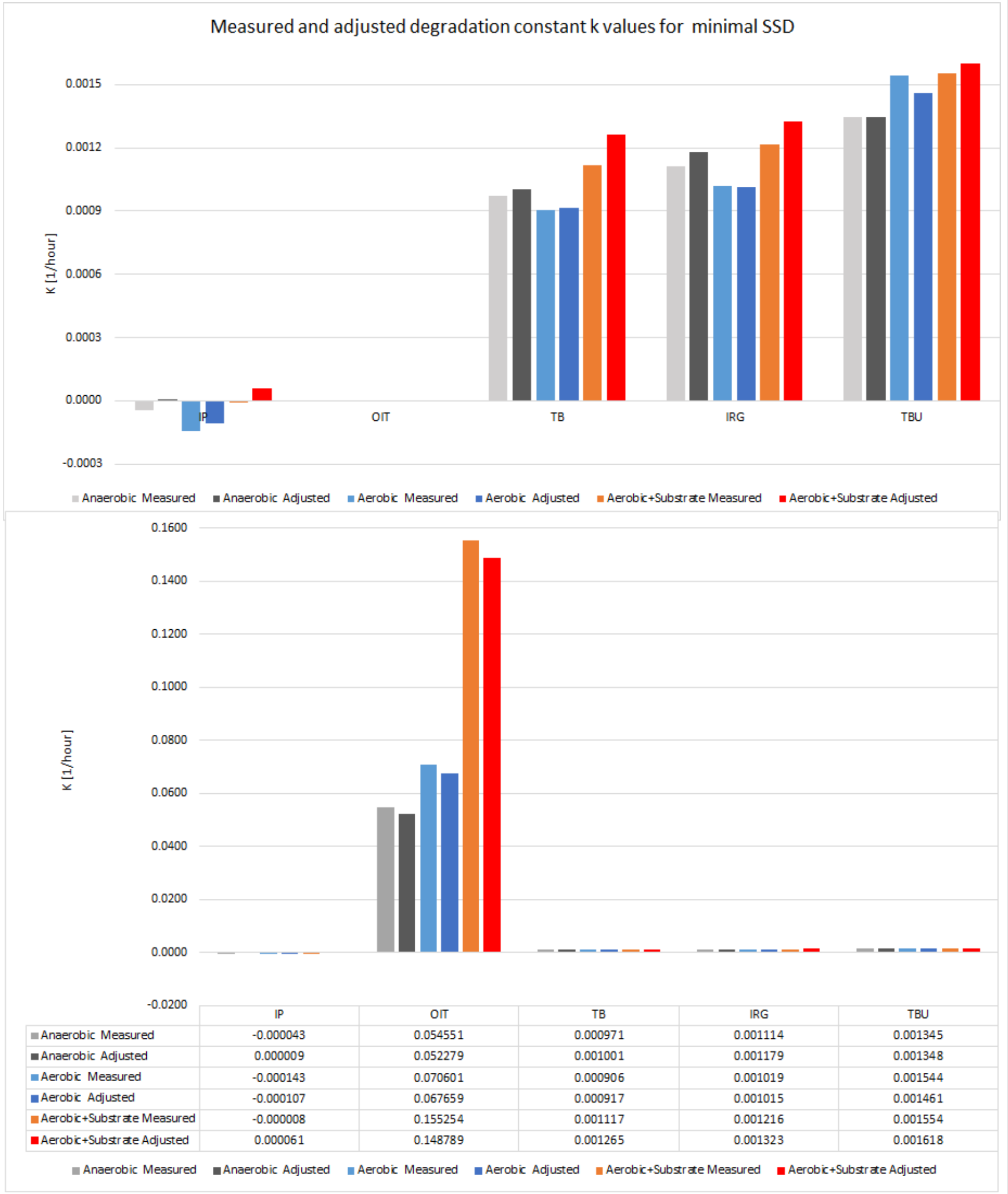

Figure 3: Measured and adjusted degradation constant $\left(\mathrm{h}^{-1}\right)$ for minimal standard square deviation. 
Citation: Chand R, Tulucan T, Aburlacitei M (2018) Investigation of Biocide Biodegradation in Wastewater under Laboratory Set-Up in Anaerobic, Aerobic and Aerobic with Substrate Conditions. J Civil Environ Eng 8: 295. doi: 10.4172/2165-784X.1000295
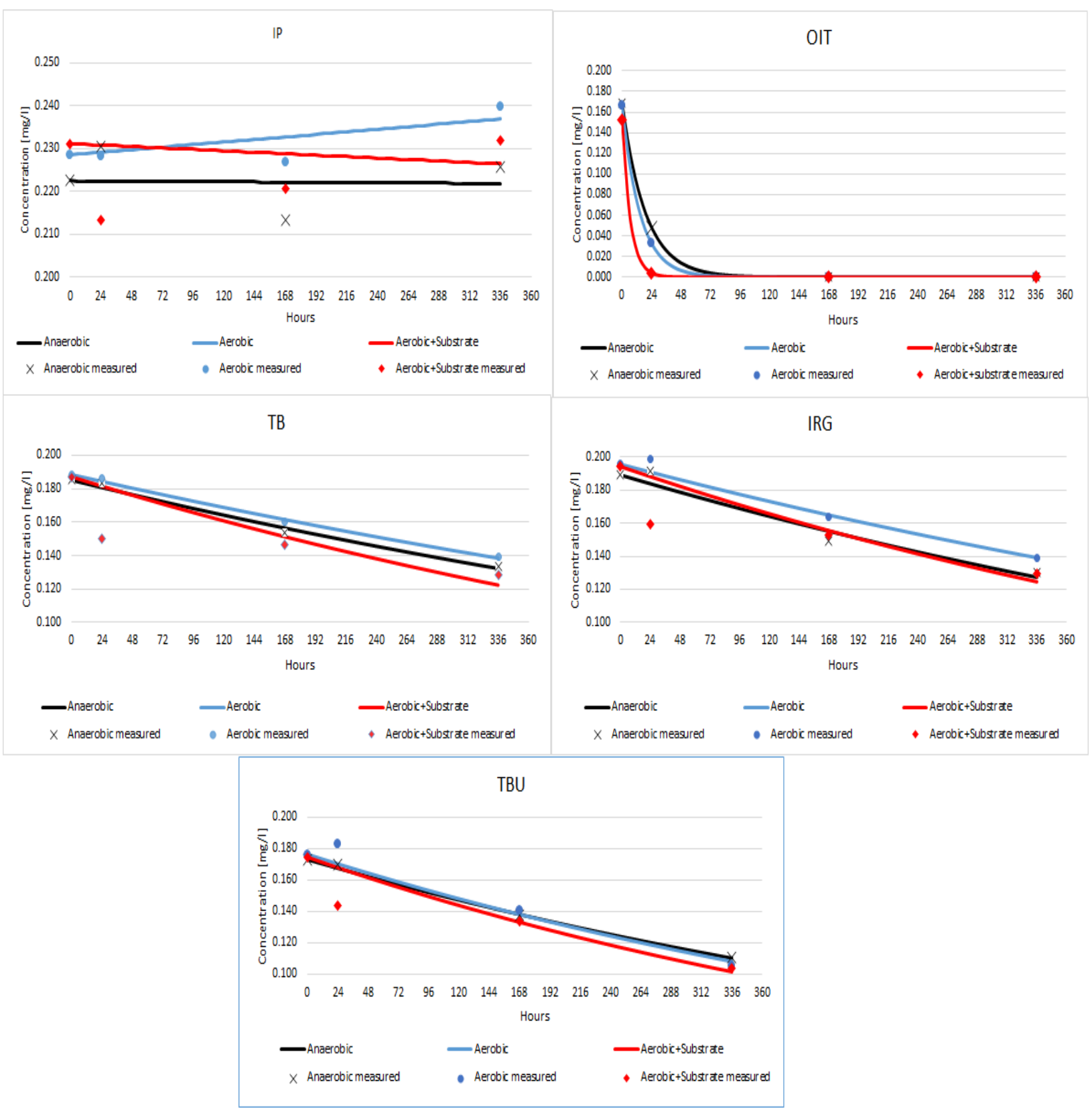

Figure 4: Best fit curve from modeled and measured concentration.

\section{Adjusted biodegradation constant and best fit biodegradation curve}

In order to get a better fit curve from analytical modeling for biodegradation, the measured (experimental) values and modeled values with respective time were adjusted. It has been done by minimizing the standard square deviation (SSD) in between these two parameters. The adjusted biodegradation rate constant $\left(\mathrm{k}_{\text {adj }}\right)$ for the best fit modelled curve with the computed values from the experiment are presented in Table 6 . The difference in between measured and adjusted biodegradation constant values has been shown in Figure 3.

Again, the adjusted biodegradation constant $(\mathrm{k})$ values were used to get best fit modeled curve from first order biodegradation.
As shown in Figure 3, difference of standard square deviation (SSD) in between measured and adjusted degradation rate constant is 0.000052 $\mathrm{h}^{-1}, 0.000036 \mathrm{~h}^{-1}, 0.000069 \mathrm{~h}^{-1}$ respectively for anaerobic, aerobic and aerobic with substrate condition for degradation of IP. OIT has greatest degradation rate constant for aerobic with substrate condition. The difference between measured and adjusted constant rate is $0.0023 \mathrm{~h}^{-1}$, $0.003 \mathrm{~h}^{-1}$ and $0.0065 \mathrm{~h}^{-1}$ at anaerobic, aerobic and aerobic with substrate conditions. However, TB, IRG and TBU lesser variation in standard square deviation in between them and within three set up laboratory conditions. The difference in SSD for TB, is $0.00003 \mathrm{~h}^{-1}, 0.000011 \mathrm{~h}^{-1}$, $0.000148 \mathrm{~h}^{-1}$; for IRG is $0.000065 \mathrm{~h}^{-1}, 0.000004 \mathrm{~h}^{-1}, 0.000107 \mathrm{~h}^{-1}$; for TBU is $0.000003 \mathrm{~h}^{-1}, 0.000083 \mathrm{~h}^{-1}, 0.000064 \mathrm{~h}^{-1}$ in anaerobic, aerobic and aerobic withsubstrate conditions respectively. Best fitted curve after 
adjusting the degradation constant for selected biocides are presented hereunder in Figure 4.

Figure 4 shows the best fitting curve for selected biocides from modeled and measured concentration where we can observe IP has inclining graphics for aerobic condition, showing negative result but in other laboratory conditions it is slightly decreasing. However, the drastic changing curve for the OIT gives non detectable amount within 24 to 72 hours of the experiment run. For rest of the biocides TB, IRG and TBU are decreasing gradually with higher rate in aerobic with substrate condition.

\section{Conclusion}

Waste water treatment plant could be one of the major point source for chemical discharge including biocides into the recipients. On the other hand, it has consequential effect in reducing such pollutants in the case they are removed at the waste water treatment plant. For this purpose engineering set ups including both physical structures and bio-chemical processing are needed.

This study found that the rate of biodegradation for selected biocides is smaller in comparison to readily biodegradable waste in other wording, biocides require more time to degrade compared with simpler organic compounds. With addition of substrate a faster decrease of biocide concentration was noticed in all samples, suggesting the presence of co-metabolism processes where bacteria eating food coincidently consume the biocides.

Therefore, wastewater treatment designs can address either increasing the retention time, or enhancing the biodegradation processes by adding substrate. It remains to be seen how these measures will affect the treatment processes, not only in terms of efficiency but also in terms of costs.

By comparing different biocide concentrations over time, in three different conditions, it has been observed that the biodegradation can be expressed by using the first order rate constants, 'k'. In this study, laboratory experiment shows that Isoproturon (IP) is not biodegradable over time. However, the other biocides investigated are biodegradable, among these Octyl-isothiazolinone (OIT) is significantly biodegraded in all three conditions. The other three biocides, Terbutryn (TB), Cybutryne, Irgarol (IRG) and Tebuconazole (TBU), investigated are slowly biodegradable. From these three conditions experimented, the highest biodegradation rate is achieved under aerobic plus substrate condition.

It has been noticed that there is sudden reduction in biocides concentration in the beginning stage which is supposed to be due to adsorption phenomena and also claim for the recovery of concentration. OIT has highest recovery and adsorption amount than the others.

The obtained biodegradation constant ' $\mathrm{k}$ ' values from the laboratory experiment has been modeled using first order kinetics and later the biodegradation curve has been fitted by statistical method by lowering the standard square deviation (SSD) in between modeled and computed ' $\mathrm{k}$ ' values.

\section{References}

1. Maillard JY (2005) Antimicrobial biocides in the healthcare environment: efficacy, usage, policies, and perceived problems Ther Clin Risk Manag 1: 307320

2. Bollmann UE, Tang C, Eriksson E, Jonsson K, Vollertsen J, et al. (2014) Biocides in urban wastewater treatment plant influent at dry and wet weather: Concentration, mass flows and possible sources. Water Res 60: 64-74.

3. European Parliament and Council (2003) Directve 2013/39/EU amending directives 2000/60/EC and 2008/105/EC as regards priority substances in the field of water policy. Official J Eur Commun 226: 1-27.

4. Lister $\mathrm{J}$ (1867) The antiseptic system and a new method of treating compound fracture, abscess, etc. Lancet. 1: 326, 257, 387, 507.

5. Craig CP (1986) Preparation for the skin for surgery. Infection Control 7: 257-258.

6. Semmelweis I (2004) The etiology, concept and prevention of childbed fever Isis 75: 442-443.

7. Patryn R, Jarosz MJ, Szubzda AW, Sak J, Pawlikowski J (2011) Consideration on Directive 98/8 of the European Commission-the biocide directive. Ann Agr Environ Med 18: 452-458.

8. Sasatsu M, Shimizu K, Noguchi N, Kono M (1993) Tricosan-resistant Staphylococcus aureus.. Lancet 341:756.

9. Heath RJ, Yu YT, Shapiro MA, Olson E, Rock CO (1998) Broad spectrum antimicrobial biocides target the Fabl component of fatty acids synthesis. J Biol Chem 273: 30316-30320.

10. Netherland Nutrition Centre (1999) Hygiene Code for private households. Based on the Dutch situation.

11. Kresmann S, Arokia AHR, Koch C, Sures B (2017) Ecotoxicological potential of the biocides terbutryn, octhilinone and methylisothiazolinone: Underestimated risk from biocidal pathways? Sci Total Environ 625: 900-908.

12. Jelic A, Fatone F, Fabio SD, Petrovic M, Cecchi F (2012) Tracing pharmaceuticals in municipal plant for integrated wastewater and organic solid waste treatment. Sci Total Environ 433: 352-361.

13. Singer H, Jaus S, Hanke I, Luck A, Hollender J, et al. (2010) Determination of biocides and pesticides by on-line solid phase extraction coupled with mass spectrometry and their behaviour in wastewater and surface water. Environ Pollut 158: 3054-3064.

14. Gasperi J, Geara D, Lorgeoux C, Bressy A, Zedek S, et al. (2014) First assessment of triclosan, triclocarban and paraben mass loads at a very large regional scale: Case of Paris conurbation (France). Sci Total Environ 493: 854-861.

15. Liu WR, Yang YY, Liu YS, Zhao JL, Zhang QQ, et al. (2017) Biocides in the river system of a highly urbanized region: A systematic investigation involving runoff input. Sci Total Environ 624: 1023-1030.

16. Liu WR, Yang YY, Liu YS, Zhang LJ, Zhao JL, et al. (2017) Biocides in wastewater treatment plants: Mass balance analysis and pollution load estimation. J Hazard Mater 329: 310-320.

17. Wick A, Fink G, Ternes TA (2010) Comparison of electroscopy ionization and atmospheric pressure chemical ionization for multi-residue analysis of biocides, UV-filters and benzothiazoles in aqueous matrices and activated sludge by liquid chromatography-tandem mass spectrometry. J Chromatogr 1217: 2088-2103.

18. Peng X, Huang Q, Zhang K, Yu Y, Wang Z, et al. (2012) Distribution, behaviou and fate of azole antifungals during mechanical, biological and chemical treatment in sewage treatment plants in China. Sci Total Environ 426: 311-317.

19. Wangler TP, Zuleeg S, Vonbank R, Bester K, Boller M, et al. (2012) Laboratory scale studies of biocides leaching from facade coatings. Build Environ 54: 168-173.

20. Celis E, Elefsiniotis P, Singhal N (2008) Biodegradation of agricultural herbicides in sequencing batch reactors under aerobic or anaerobic conditions. Water Res 42: 3218-3224.

21. Sperling MV. Biological wastewater treatment series. Volume two. Basic Principles of Wastewater Treatment. Department of Sanitary and Environmental Engineering Federal University of Minas Gerais, Brazil; 2007.

22. Aziz CE, Borden RC, Coates JD, Cox EE, Downey DC, et al. (2009) In situ bioremediation of perchlorate in groundwater. SERDP/ESTCP Environmenta Remediation Technology.

23. Ternes TA, Joss A, Siegrist $H$ (2004) Scrutinizing pharmaceuticals and personal care products in wastewater treatment. Environ Sci Technol 38: 392-399.

24. Ekblad M (2014) Stormwater treatment-sorption of organic biocides from paints and renders.

25. Cooke CM, Shaw G, Collins CD (2004) Determination of solid-liquid partition coefficients $(\mathrm{Kd})$ for the herbicides isoproturon and trifluralin in five UK agricultural soils. Environ Pollut 132: 541-552.

26. Perrin-Ganier C, Schiavon F, Morel JL, Schiavon M (2001) Effect of sludgeamendment or nutrient addition on the biodegradation on the herbicides isoproturon in soil. Chemosphere 44: 887-892. 
Citation: Chand R, Tulucan T, Aburlacitei M (2018) Investigation of Biocide Biodegradation in Wastewater under Laboratory Set-Up in Anaerobic, Aerobic and Aerobic with Substrate Conditions. J Civil Environ Eng 8: 295. doi: 10.4172/2165-784X.1000295

27. Singh A, Ward OP (2004) Biodegradation and Bioremediation. Soil Biology.

28. Dow Chemical Company (2012) Product Safety Assessment, 2- Octyl-2Hisothiazol-3-one (OIT).

29. Bollmann UE, Minelgaite G, Schlusener M, Ternes T, Vollertsen J, et al. (2016) Leaching of terbutryn and its photodegradation products from artificial walls under natural weather conditions. Environ Sci Technol 50: 4289-4295.

30. van Wezel AP, van Vlaardingen $P$ (2004) Environmental risk limits for antifouling substances. Aquat. Toxicol 66: 427-444.

31. Olsen SM, Kiil S, Dam-Johansen K, Pedersen LT, Hermann MH (2009) Controlled release of environmentally friendly antifouling agents from marine coatings.

32. European Commission. Cybutryne EQS dossier. ; 2011.

33. Strickland TC, Potter TL, Joo H (2004) Tebuconazole dissipation and metabolism in Tifton loamy sand during laboratory incubation. Pest Manag Sci 60: 703-709.

34. Kahle M, Buerge IJ, Hauser A, Muller MD, Poiger T (2008) Azole fungicides:
Occurrence and fate in wastewater and surface water. Environ Sci Technol 42:7193-7200.

35. Kortekaas SPW (2010) Behaviour and fate in the environment; behaviour in surface water, sediment and sewage treatment plant (STP).

36. WHO (1996) Isoproturon in drinking water. Guidelines for drinking water quality.

37. Wealth Ocean Inc. (2014) Isothiazolinones, California, USA.

38. Williams TM, Jacobson AH (1999) Environmental fate of isothiazolone biocides. Rohm and Haas Co., Spring House, PA (US).

39. CECBP (2009) Consideration of potential designated chemicals - Octhilinone.

40. Brandhorst MD (2006) Ecotoxicological evaluation of the herbicide terbutryn pp. 1-59.

41. Talja KM, Kaukonen S, Kilpi-Koski J, Malin I, Kairesalo T, et al. (2008) Atrazine and terbutryn degradation in deposits from groundwater environment within the boreal region in Lahti, Finland. J Agric Food Chem 56: 11962-11968.

42. Thomas KV, Brooks S (2010) The environmental fate and effects of antifouling paints biocides. Biofouling 26: 73-88. 